\title{
The Illusion of Choice: Parallels between the Home Cinema Industry of the 1980s and Modern Streaming Services
}

\author{
Adam L. Miller* \\ Aichi Shukutoku University, Aichi Pref, Sakuragaoka Ward 23, Nagoya City, Japan
}

*Corresponding Author: Adam L. Miller, Aichi Shukutoku University, Aichi Pref, Sakuragaoka Ward 23, Nagoya City, Japan

\begin{abstract}
This research article hopes to look at the prolific rise of VHS and home cinema in the 1980s; how it altered the viewing experiences of film-lovers, how the industry adapted to accommodate to this new market and how these viewing habits that started decades ago, still resonate today. The article will be drawing parallels between the VHS based home cinema of the 1980s to the subscription based streaming applications which are prolific today, using Netflix Inc. as the main point of focus.
\end{abstract}

Keywords: "Film Studies;," "VHS;, "Home Cinema;" "Streaming” "Netflix;,"

\section{INTRODUCTION}

The article will go on to explore how the sudden emergence of home cinema in the 1980s allowed viewers to explore films, genres, filmmakers and content that is often referred to as 'world cinema' that they may have otherwise been unaware of. It will be argued that streaming services have the same potential to expose viewers to a wide variety of content, but this potential may not be being fulfilled, as it is not in the best interests of streaming services to have viewers searching through unfamiliar territory. Furthermore, the article will look into how advanced algorithms keep customers' viewing experience familiar and enjoyable, effectively crippling the opportunity for viewers to stumble across content outside of their defined comfort zones.

\subsection{The Concept of Home Cinema}

Home cinema has a confusing and convoluted history, with different companies and technologies vying for dominance. Movie studios were also extremely reluctant to begin with when it came to licensing their films to magnetic tape, as they feared it would damage their box office takings; would people pay for a cinema ticket if they knew the film could be theirs to own and watch at their leisure in their own home in the near future? Andre Blay is widely regarded as the first person to gain distribution rights to put Hollywood films on tape, the only studio which gave Blay access to their films was $20^{\text {th }}$ Century Fox, who offered him 50 titles at 6000 USD each. But even Blay was unaware of the potential of the rental market:

'He [Blay] based his business on sales rather than rental. In fact, he made retailers sign an agreement that they would not rent the tapes, as he feared that they would then stop reordering tapes from him., ${ }^{1}$

For the sake of simplicity and the chance to focus on the core argument of this article, this study will jump ahead to the mid-1980s, by which time a number of studios had not only licensed out their films, but some even released their own home cinema range, whilst video stores had become prolific and the renting culture all but second-nature to the populace. The home cinema culture of the United States of America will be the prime focus, as there seems to be a greater wealth of figures and articles to draw from. Lastly, this article looks exclusively at the success of the VHS format, and does not draw upon any other technologies that were present in the 1980s.

\section{THE NORMALIZATION OF THE VHS}

\subsection{How the Home Cinema Market was Established and Altered}

In an exceptionally short period of time, home cinema went from being a fringe luxury for the techsavvy, to a household item: 
'There were only 1.9 million American households with a VCR in 1980, there were 64.5 million ten years later; this represents a shift from about 2 percent of the population to over 70 percent. ${ }^{2}$

As people became more comfortable with home cinema, rental stores flourished, from Mom and Pop stores to gigantic franchises, almost every high street nationwide had some kind of video rental shop. This sudden boom in available content gave customers a selection of genres, directors and even world-cinema titles that they may have otherwise not discovered.

This proliferation of choice, which may not seem too extensive by today's standards, was evergrowing in the 1980s, and a huge step up from having only theatrical releases and televised movies to enjoy, the latter of which having been interjected with commercials, edited to fit into a certain time slot and even censored to keep it age-appropriate. Home cinema not only allowed people to watch films they knew and loved at any given time, it also allowed them to be more adventurous in their film selections, and this enthusiasm for the unknown is even reflected in the top 10 lists of each year:

1980 Top 10 selling VHS

- The Godfather, Francis Ford Coppola, 1972

- Saturday Night Fever, John Badham, 1977

- Superman, Richard Donner, 1978

- $\quad M * A * S * H$, created by Larry Gelbert, $1972-1983$

- The Godfather II, Francis Ford Coppola, 1974

- Blazing Saddles, Mel Brooks, 1974

- 10, Blake Edwards, 1979

- Grease, Randal Kleiser, 1978

- $\quad$ The Sound of Music, Robert Wise, 1965

- Halloween, John Carpenter, $1978^{3}$

Looking at the most popular films in 1980, the majority were released within a year or two of the point of sale, with Blazing Saddles (1974), The Godfather (1972), The Godfather Part II (1974) and $M * A * S * H(1972)$ all being less than a decade old and extremely popular, mainstream Hollywood films/series. Perhaps the only film that could be considered classic cinema by the contemporary audience would be The Sound of Music (1965), which was a film that remained so popular it was still very much part of the public zeitgeist.

Jumping forward to 1989 , and the top selling VHS are much more diverse in nature, moving away from being exclusively Hollywood hits, to a variety of formats, genres and periods:

- Cinderella, Clyde Geronimi, Wilfred Jackson, Hamilton Luske, 1950

- E.T. - The Extraterrestrial, Steven Spielberg, 1982

- Jane Fonda's Complete Workout, 1988

- Moonwalker, Jerry Kramer, Jim Blashfield, Colin Chilvers, 1988

- Callanetics, Patricia Birch, 1986

- Dirty Dancing, Emile Ardolino, 1987

- The Wizard of OZ, the 50th Anniversary Edition, Victor Fleming, 1939

- Lethal Weapon, Richard Donner, 1987

- U2 Rattle and Hum, Phil Joanou, 1988

- Pink Floyd: Delicate Sound of Thunder, Wayne Isham, 1989

This list includes contemporary blockbusters, such as Dirty Dancing and Lethal Weapon (1987), music videos from Pink Floyd, U2 and Michael Jackson, and exercise tapes from Jane Fonda (who held at least one top 10 spot in the top selling VHS every year since 1982) and the Callanetics series. 
Interestingly enough, it also services some nostalgia as well, with a $50^{\text {th }}$ Anniversary special release of The Wizard of $\mathrm{Oz}$, and Disney's classic animation, Cinderella, which was released 39 years before the point of sale, topped the charts.

Furthermore, this diversity also demonstrates the increasing diverse set of demographics that were successfully targeted by the home cinema market. With the exceptions of Superman and The Sound of Music, the films in the 1980 top 10 were aimed exclusively at adults, and broadly speaking, a male audience. In contrast, the 1989 list has films targeted at children (Cinderella), family films (The Wizard of Oz, E.T. - The Extraterrestrial), women (Jane Fonda's Complete Workout, Callanetics) and adult audiences (Lethal Weapon and Dirty Dancing). Michael Jackson, U2 and Pink Floyd also represent a diverse musical taste. These "Top 10s"epitomize the expanding diversity of VHS and the multitude of markets it was able to target and profit from.

\subsection{Niche Markets}

On a much smaller scale, the Home Cinema market also opened up potentially profitable niche markets for independent studios, some aiming to promote what they saw as important cinema to a welcoming audience (the Criterion Collection, Kino Lorber, Zeitgeist etc.), others hoping for a 'tentpole franchise' a low budget franchise that was profitable enough to support the entire company (New Line Cinema, Miramax etc.), and the prolific straight-to-video market, which made inexpensive genre or pornographic films to turn a quick yet substantial profit (Shapiro-Glickenhaus Entertainment, Concord Pictures etc.). By and large, these films did not gross as much as the more mainstream entertainment produced by the established studios (or even their archived movies), but they did find an attentive audience, one which helped these studios flourish and grow alongside the increasing popularity of home cinema, each carving out a specific, small but profitable corner of the market.

Although only anecdotal evidence, filmmakers of the time stressed how high demand was, and whilst standards may have slipped, this high turnover of independent films gave rise to cult classics and surprise runaway successes that may not have been green-lit by more traditional production companies. Whilst Ted Hope is now a well-respected Hollywood producer, his first credited work was as an associate producer on the 1987 horror film, Doom Asylum(Richard Friedman, 1987), and his account of the making of that film is very telling in how urgency and tight deadlines forced these films to be creative and flourish in their budgetary and time restraints:

'Steve Menkin, a friend, called me because they had put together $\$ 100,000$ to make Doom Asylum, but they didn't have a script or cast. They had to shoot for four weeks because of the delivery date. We basically ran actor friends of ours up and down an abandoned insane asylum's hallways. We used techniques like shooting in a location you can control; use natural lighting wherever possible; trying to use youthful characters because they're non-SAG (screen actor's guild) and you could afford them; cover things in as few shots as possible, so you're not doing dolly moves, doing walk-and-talks to the camera or away from the camera [...] It's not how people dreamed of making movies. It was filmmaking by necessity. ${ }^{4}$

This 'filmmaking by necessity' dictated an aesthetic that spoke to a certain audience; using natural lighting, long shots and handheld camerawork when necessary added to the style, whilst using actors who were not part of the Screen Actor's Guild allowed for unknown actors to carve out a successful career, Doom Asylum for example was the first credited role for Kristin Davis, who would later become inseparable from her role as Charlotte in HBO's long running series, Sex and the City. The fact that the film secured finance before it had even a cast or a script showed how confident producers were that films could claw back a profit in the home video market, and this gave space to some unconventional films to find an audience and cross-over into mainstream success, and even break the mold of what was expected of independent films.

Sex, Lies and Videotape (Steven Soderbergh, 1989) was one such movie, which had a budget of $\$ 1.2$ million, and grossed $\$ 24.7$ million at the box office. As well as being a financial success, it was also critically acclaimed, winning an array of awards, most notably the Palme d'Or at the Cannes Film Festival in 1989. But whilst it idpps now seen as a classic film, it had a similar vetting process to other independent films of the time, i.e. it had to be titillating. However, it slowly changed to become the finished product we are familiar with today. Larry Estes signed off on some of the most iconic films of the 1980s, and although he was a little wary of the script's oddities, he saw potential: 
'Unusual is ok if it's sexy. We all felt like it was unlike anything we had read. We hoped Sex, Lies would make us 20 or 30 per cent on our money [...] In the late 80 s, if something had sexual content, you were almost guaranteed to make a certain amount of money. ${ }^{, 5}$

So whilst the director, Steven Soderbergh, may have secured the financing for his film on the promiscuity the title (and later the promotional images) promised, he sculpted the film to be less overtly erotic and more suggestive and sensual, a move that many thought would simply alienate a niche market, rather than attract a new, broader demographic. Estes continues:

'It became more viewer friendly but until Sundance, we didn't think it would be anything more than another video movie that we put out for a million bucks. But after that, producers started to feel, "Now I don't have to just make movies with a bloody knife and a partially clad woman on the video box to get a deal. I can start doing riskier and edgier stuff." 6

\subsection{Opening up New Markets}

Following the success of Sex, Lies and Videotape, independent cinema started to expand into what some would call more legitimate movie making, inspired by exploitation and low-budget horror films, but no longer relying purely on cheap thrills or excessive violence (although these were still utilized), and Estes was given the freedom to work with creatives who are still very much active and respected to this day, a stark contrast from being 'guaranteed to make a certain amount' with the mere promise of nudity.

Parallel to the aggressive expansion and oft-changing face of independent cinema, the early 1990s also saw a huge influx of world cinema, perhaps most notably the increasing demand for Japanese animation, or anime, which was brought international notoriety through the release of the 1989 film, Akira (Katsuhiro Otomo, 1988):

'A brilliant dystopian science-fiction work, Akira was a groundbreaking film, not only because of its imaginative cyberpunk plotting and cutting edge animation, but also because it was the first anime to be taken seriously as an artistic work in both Japan and the West. ${ }^{7}$

Much like the breakaway success of Sex, Lies and Videotape, which opened up the independent cinema market and made it appear more accessible to a wider audience, Akira created a loyal and curious viewership, who would seek out past animations, and secure a profitable market that ensured the anime industry would continue to make more films in the future, ranging from niche markets, to films that would later gain the attention (and financing) of Disney:

'With its artistic depth and dark contemporary sensibility, Akira helped to usher in a new era, in which Japanese animation and its related medium manga [Japanese comic strips] would gain viewers and readers worldwide to become a thriving alternative to American popular culture. ${ }^{8}$

So in less than a decade, VHS had moved from being a convenient way to watch the contemporary hits at home, to opening up huge independent markets, securing a new generation of dynamic filmmakers, introducing world cinema to mass audiences and offering diverse entertainment beyond movies, including exercise and music videos. As the 1990s progressed, the home cinema market continued to expand, and having a device to watch films at home became a staple. But VHS did not have a guaranteed seat at the table, as was proved by the 1995 launch of DVDs and with the turn of the millennium, the increasing popularity of subscription based business models and digital streaming.

\section{Streaming SerVices}

\subsection{Netflix Inc.}

There are now dozens of subscription based services that offer television shows and movies on demand, individual television networks have even started up their own streaming services to give audiences constant access to their past and present programming. This means that almost any contemporary and/or mainstream film is easily accessible once it hits the home cinema market, whilst at the height of the rental stores' popularity, if the VHS or DVD you wanted to watch had all its copies rented out, you had to wait for a copy to return.

One could argue that the very real threat of not finding the movie you wanted to watch at the video store has now been eliminated, which in itself may have seemed like an annoyance, but may well have 
led to people going outside of their comfort zone and discovering previously unknown films or filmmakers.

Whilst there are dozens of companies that stream content, this article will focus on Netflix, arguably the most prominent and possibly most tenacious organization in the current home cinema market. Netflix has evolved from home delivery of DVDs, to online streaming, to creating original content that is both diverse and immensely popular. They now work alongside large movie studios like Disney (via their Marvel series' that are tied to the Marvel Cinematic Universe's on-going narrative) and TV channels, which allows shows to stream on Netflix soon after their televised airing.

Netflix have long aimed to offer their users a wide range of titles to choose from, making convenience one of their biggest selling points, and moving away from DVDs delivered physically in the mail and towards online streaming, they can offer a wider selection than ever before:

'Netflix, Inc. ('Netflix', 'the Company', 'we', or 'us') is the world's leading internet television network with over 93 million streaming members in over 190 countries enjoying more than 125 million hours of TV shows and movies per day, including original series, documentaries and feature films. Our members can watch as much as they want, anytime, anywhere, on nearly any internetconnected screen. Members can play, pause and resume watching, all without commercials or commitments. ${ }^{9}$

The content that is available on demand, at any time, dwarfs the libraries of even the most gargantuan video rental store. Furthermore, there is no time-scale within which a movie or TV show must be watched, meaning no late fees or other punishments for the less punctual of users. Whilst Blockbuster believed their more personal touch may have secured a loyal customer base ('We believe our offering of both in-store and online movie and game rental and in-store retail products has uniquely positioned us to meet the entertainment needs of our customers. ${ }^{, 0}$ ) the simple convenience and seemingly endless selection meant that subscription based entertainment services were all but guaranteed to outlast the tactile rental system, which may very well seem antiquated to the newest generation of film lovers today.

This article will now look at these new models for viewing content at home (or on the go) and put forward the argument that we as customers are presented an illusion of endless variety, but in fact are analyzed and fed titles that we have a penchant for already, and so our viewing habits may stagnate. Again, Netflix Inc. will be the main focus of this part of the study, as they arguably have the most advanced algorithms and a growing dependence on producing their own content and not just relying on buying film-rights from third parties.

\subsection{Achieving Highly Competitive Results}

Over recent years, Netflix has been putting more importance on original and exclusive content, which is both incredibly popular and a successful draw in both retaining existing customers and attracting new ones. Netflix is able to push their own properties with in-app commercials, notifications sent directly to customer's mobile devices, prime positioning in their 'Recommendations' section and larger thumbnails, all of which helps snatch the viewers' attention away from more familiar Hollywood films.

They have also constructed content that fits neatly into certain genres, including a wide range of comedy specials, situation comedies, children's shows, dramas and quirky independent cinema. These well-defined categories are extremely important to Netflix, as they feed information into their 'Recommendations' an algorithm unique to each user and one which predicts what a certain account holder will like based on their past viewing habits, a feature they place a real faith in:

'If our recommendation and merchandising technology does not enable us to predict and recommend titles that our members will enjoy, our ability to attract and retain members may be adversely affected. ${ }^{11}$

This feature serves Netflix in two very beneficial ways, firstly, it draws out content a user is likely to enjoy, saving them the bother of searching through their extensive library, and secondly, the more accurate the recommendations are at presenting content the user enjoys, the more trusting the user will be of any titles that are presented to them in the future; which in turn means that if Netflix places their 
own content in the Recommendations section, users will be more inclined to watch it. They were so keen to improve their algorithm, they offered a 1 million USD prize to anyone who could improve on the system they had in place in 2006:

'The Netflix Prize sought to substantially improve the accuracy of predictions about how much someone is going to enjoy a movie based on their movie preferences. ${ }^{12}$

Whilst securing a statement from Netflix explaining how their algorithm is put together was not possible, following the competition, three very extensive reports were released and they go into the extreme complexities of the systems put in place to help recommend titles to users, and how important these programmes are Netflix's success:

'Recommender systems give companies a way to effectively target their products and services, thus improving their potential for revenue. These systems are also interesting from the customer standpoint because they are presented with alternatives focused on their likes and dislikes, thus lowering the number of unwanted propositions. One of the keys to building a good recommender system is to find meaningful and systematic patterns in the data, in order to identify the concrete tastes of customers. ${ }^{13}$

This succinctly sums up the two main benefits for these complex systems, firstly they offer users a more streamlined and personalized experience using the software, one which they are more likely to continue using, and secondly (and perhaps more importantly), it has the potential to greatly improve the income of the company which puts these systems in place. It is obviously a very difficult task to discover the 'concrete tastes of customers' and a wide variety of approaches were tried and tested:

'A key to achieving highly competitive results on the Net- flix data is usage of sophisticated blending schemes, which combine the multiple individual predictors into a single final solution[...]Our blending techniques were applied to three distinct sets of predictors. First is a set of 454 predictors, which represent all predictors of the BellKor's Pragmatic Chaos team for which we have matching Probe and Qualifying results. Second, is a set of 75 predictors, which the BigChaos team picked out of the 454 predictors by forward selection. Finally, a set of 24 BellKor predictors for which we had matching Probe and Qualifying results. ${ }^{, 14}$

All of these 'predictors' were rigorously tested and examined, and the combination of an overarching set of results from 454 predictors, a selection of 75 predictors and a honed set of 24 predictors, gave a better impression of what content users may be interested in based on their viewing habits, the ratings they gave and which titles they were naturally drawn to.

\subsection{Wide Selection, Narrow Choice}

So whilst Netflix inarguably has an extensive catalogue of titles to choose from, and the programs they have in place make perfect business sense, the very fact that the company aims to suggest titles it believes the user will like could arguably have a detrimental effect on the scope of titles a user is likely to watch. In stark contrast to the growing variety of the Top 10 VHS rentals of 1980 and 1989, the influx of world cinema and the booming independent cinema industry of the 1980s, modern users of streaming services are more likely to be offered content that will seem familiar and comfortable, rather than experiment with the unknown or unfamiliar.

Whilst this is may sound merely like conjecture, there is no denying the importance Netflix has placed on the accuracy of their algorithms, as they have invested millions of dollars in improving their systems to make them more effective. Many filmmakers also have trouble with the idea that their products will be deconstructed and assimilated with other content that the algorithms deem similar, as filmmaker Jeff Baena explained an on episode of Marc Maron's podcast, WTF:

'The way media is so disseminated today, everything is marketing, everything is labeling, everything is compartmentalizing, and so your experience is almost pre-digested before you experience it. ${ }^{15}$

Baena's description is both concise and extremely accurate, any product that is hosted on Netflix will be broken down into a number of 'labels'(or predictors) which can potentially link them to other, similar products. These tags include (but are not exclusive to) genre, director, cast, source material and even year of release. From personal experience, after watching Escape from Alcatraz (Don Siegel, 1979), I was presented with an entire tab filled with television shows and films all centered around breaking out of prison, so watching and positively rating just one product, immediately altered the 
properties that were presented to me; which, it could be argued, is having your films 'pre-digested' as they snuggly fit into a selection you have shown to have a fondness for.

This proliferation of content does not only arguably narrow the content viewed by users, it also has the potential to actually damage the independent market and limit the amount of low budget, independent films that are created. It may seem counter-intuitive to tie more channels of distribution to less opportunities to independently created content, but the reality is that with a heavily fragmented market, securing an audience (and financing) can be extremely difficult, as producer Ira Deutchman states:

'That whole business model in the 80's where you could essentially get an independent film financed by virtue of having a certain amount of guaranteed home video units that it was going to sell [...] simply doesn't exist anymore [...] Because nobody has any numbers to back up how much business these things could potential do on all of the various platforms that are out there. ${ }^{16}$

It may seem an odd position to take that a wider selection has effectively narrowed users' intake, or that multiple new channels of distribution have stifled production of independent cinema producers, but the streaming services of today have the same aim as that of the home cinema in the 1980s, to create a viewership and earn money. Whilst home cinema and VHS allowed for a plethora of different markets to take advantage of a growing and curious market, streaming services of today have stiff competition to offer the best, the newest and the widest selection of content. Furthermore, they are placing ever more importance on developing their own exclusive content, which in itself has the potential to draw in new users.

\section{CONClusion}

Whilst video rental stores of yesteryear hold a strong nostalgic power over those that still remember them, and allowed for new markets to spring up, the reality is that if users of streaming services are consistently presented with content they don't enjoy, they will stop subscribing. Whereas, if they are consistently pleased with the titles that are selected for them, this stockpiling of goodwill may mean they are far more likely to click on unknown titles that appear in their 'Recommendations' which may well be the independently created content that the streaming service has invested in so heavily. The potential reward of pleasantly surprising a user with a title they would not have chosen independently does not counteract the danger of disappointing them with a title they didn't like.

The business model of Netflix (and most streaming services) relies on people remaining subscribed, so the users must constantly be presented with content that they are favorable towards, the more of which they watch and like, the more accurate the algorithm for selecting similar titles in the future becomes. Whilst other titles may not be taken away from the viewers, and they can still technically watch anything from Netflix's library, it may well be harder to find such content and they will instead be shown rows of favorable genres, directors or actors they have liked in the past or even certain time periods that may scratch an itch of nostalgia. This is, I would argue, merely an illusion of choice, Netflix determines what you like and perpetually offers you something similar, making it less likely you step out of your comfort zone, as the longer a user is in their comfort zone, the longer they will subscribe to the service and the more money the service can acquire.

\section{REFERENCES}

[1] Daniel Herbert, Video Land: Movie Culture at the American Video Store, University of California Press, Ltd., Page 24

[2] Daniel Herbert, Video Land: Movie Culture at the American Video Store, University of California Press, Ltd., Page 26

[3] http://www.inthe80s.com/vidtop10.shtml

[4] Tom Roston, I Lost It at the Video Store: A Filmmakers' Oral History of a Vanished Era (expanded edition), Self-published, 2017, p.54

[5] Tom Roston, I Lost It at the Video Store: A Filmmakers' Oral History of a Vanished Era (expanded edition), Self-published, 2017, p.67

[6] Tom Roston, I Lost It at the Video Store: A Filmmakers' Oral History of a Vanished Era (expanded edition), Self-published, 2017, p.68 
The Illusion of Choice: Parallels between the Home Cinema Industry of the 1980s and Modern Streaming Services

[7] Susan J. Napier, From Impressionism to Anime: Japan as Fantasy and Fan Cult in the Mind of the West, Palgrave MacMillan, 2007, p.170

[8] Susan J. Napier, From Impressionism to Anime: Japan as Fantasy and Fan Cult in the Mind of the West, Palgrave MacMillan, 2007, p.170

[9] Netflix, Inc. Form 10-K For the fiscal year ended December 31, 2016, p.3

[10] Blockbuster Inc. Form 10-K For the fiscal year ended December 31, 2005, p.5

[11] Netflix, Inc. Form 10-K For the fiscal year ended December 31, 2016, p.9

[12] http://www.netflixprize.com/

[13] Martin Piotte Martin Chabbert, The Pragmatic Theory solution to the Netflix Grand Prize, August 2009 Pragmatic Theory Inc., page 3

[14] Yehuda Koren, The BellKor Solution to the Netflix Grand Prize, August 2009, p. 8

[15] Jeff Baena, Episode 826 WTF with Marc Maron

[16] Tom Roston, I Lost It at the Video Store: A Filmmakers' Oral History of a Vanished Era (expanded edition), Self-published, 2017, p.106

[17] Gina Keating, Netflixed: The Epic Battle for America’s Eyeballs, Penguin Group USA, 2012

Citation: Adam L. Miller. "The Illusion of Choice: Parallels between the Home Cinema Industry of the 1980s and Modern Streaming Services". International Journal of Media, Journalism and Mass Communications (IJMJMC), vol 5, no. 4, 2019, pp. 01-08 doi: http:// dx.doi.org/10.20431/2455-0043.0504001

Copyright: (C) 2019 Authors. This is an open-access article distributed under the terms of the Creative Commons Attribution License, which permits unrestricted use, distribution, and reproduction in any medium, provided the original author and source are credited. 